\title{
ADDRESSING THE CHALLENGES IN MARKETING THE SERVICES IN RURAL INDIA
}

\author{
Miss. Anicar D Manavi, \\ Asst. Professor, Department of MBA, \\ SDGS College, Hindupur-515201(AP) \\ anikarmd@gmail.com
}

\begin{abstract}
The words of Steve Jobs "it's really hard to design products by focus groups. A lot times, people don't know until you show it to them," are hundred percent true in the context of rural consumers in India especially in the case of marketing the services to them. Though the statistics reveal a significant development in rural India like increase in literacy rate, speedy expansion of infrastructure, reduction in poverty level etc, still the services availing capabilities in rural Indians are far behind. Their expectations towards services are lower than their expectations towards goods. This attitude is because of the existence of peculiar characteristics in rural Indian consumers. Some among them are less access to information on services, poor in identification of need of resources, problem of affordability, collective decision making, key role of panchayat heads and self help groups as opinion leaders and high level migration of educates etc.

But all these challenges can be overcome by producers of services by adapting villagers friendly strategies and can exploit the opportunities in rural India that were untapped for ages. For instance, to bring the rural people into the ambit of financial inclusion, the Banking system came out with Business correspondent system. This system is playing a critical role in achieving the goal of financial inclusion.Thus the reason for not able to exploit the opportunities in services market in rural areas is not because of resistant from the villager to accept the services but because of the need of more research in understanding the rural consumer behavior for services and construction the marketing strategies accordingly.
\end{abstract}

Key words: rural, marketing, consumer, services, Indians, behavior, expectations

Introduction: "Do what you do so well that they will want to see it again and bring their friends" - Walt Disney

Marketing the services in rural market is more challenging than marketing the products (goods) in rural market. The structure of Indian rural market is most complicated in nature. Villages in India are much diversified with respect to customs, traditions and needs. A service provider/seller can't even dream of making his entry into rural market with understanding this diversification of culture, demography, geography and Economy. To get a detailed view about Indian rural market one has to invest more on rural marketing research and information system. As per census of 2011, 68.67\% of Indian population resides in rural India. Once the service provider is success in catching the pulse of 
and bringing awareness among rural consumers, it's like awakening the sleeping giant.

Services Marketing: Services marketing typically refer to both business to consumer (B2C) and business to business (B2B) services, and include marketing of services like telecommunications services, financial services, all types of hospitality services, car rental services, air travel, health care services and professional services. ${ }^{4}$

Rural area: The "rural sector" means any place as per the "latest census" which meets the following criteria,

i) a minimum population of 5,000 ;

ii) at least 75 per cent of male working population engaged in non-agricultural pursuits; and

iii) a density of population of at least 400

per sq. km. (1,000 per sq. mile) ${ }^{5}$

Analysis and Discussion: The rural market in India is a huge unorganized market as well as much of it is still untapped in various domains. The rural revolution is driven by rising purchasing power, changing consumption patterns, increased access to information and communication technology, improving infrastructure and increased government initiatives to boost the rural economy. There is an immense potential in rural markets which is still waiting to be tapped ${ }^{6}$. However There are some challenges to the service sellers to enter and sustain in rural market. These challenges can be broadly classified in to i) Traditional Challenges and ii) Recent Challenges.

\section{Challenges}
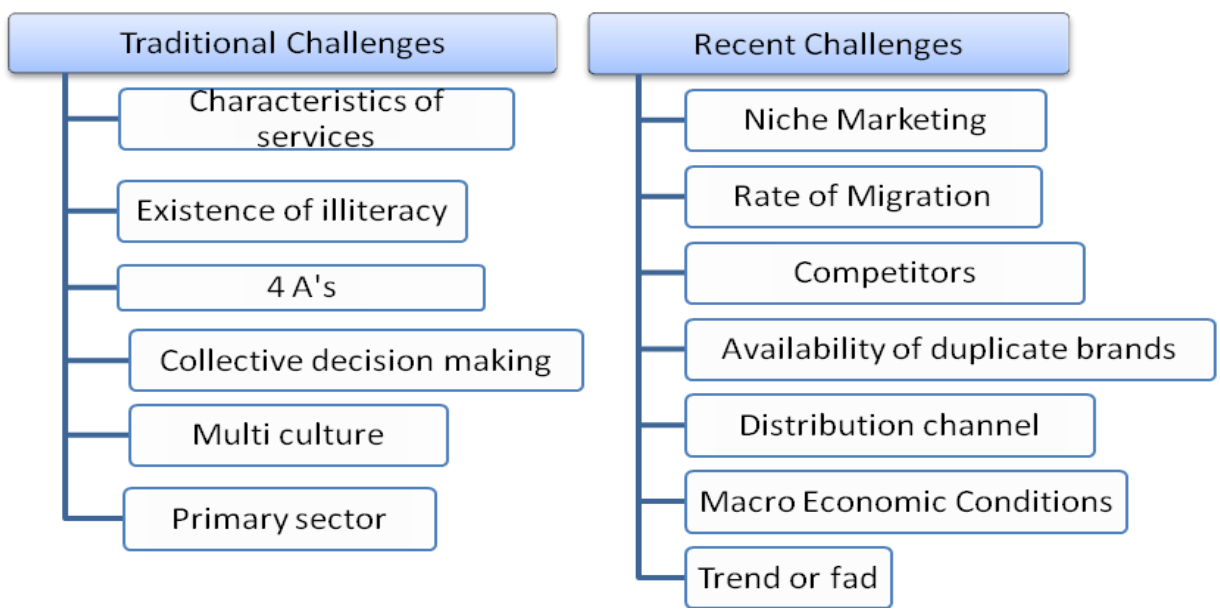
ELK

Asia Pacific Journals

Traditional Challenges: Traditional

Challenges are challenges which are there from decades. Even after a considerable changes in the statistics of rural economy of India some of the rural conditions posing challenges to service marketing. Some of them are discussed below.

1. Characteristics of Services: The basic characteristics of services (intangibility, Heterogeneity, perishability, \& Inseparability) are making tough to the marketers to explain about the services they provide. Qualities of Services either fall under experience qualities or under Credence Qualities. Thus it's very difficult to explain these with words and bring the feel of experience to customers.

In this context the audio visual aids become handy. One of the strategies is designing of advertisements which are capable of explaining the service. For instance, Kisan Call Centre advertisements which explain about and motivate the formers to utilize the agriculture consultancy service providing by Ministry of agriculture.

2. Existence of illiteracy: As per census of 2011 , literacy rate in rural India is $67.67 \%$. The level of literacy is lower compared with
ELK Asia Pacific Journals - Special Issue

ISBN: 978-81-930411-9-2

urban areas. This again leads to a problem of communication in these rural areas. Print medium becomes ineffective and to an extent irrelevant, since its reach is poor.

This problem can be addressed with the help of literates in the Self help groups or as a part of corporate social responsibility (CSR) they can undertake the responsibility of providing education to the illiterates under their respective brand names. This strategy helps the marketer for longer period in the way of increasing literates as well as creating a brand image in the minds of villagers.

\section{4 A's}

- Availability: The first challenge in rural marketing is to ensure availability of the product or service. Given the poor infrastructure, it is a greater challenge to regularly reach products to the far-flung villages. Marketer should plan accordingly and strive to reach these markets on a regular basis. Marketers must trade off the distribution cost with incremental market penetration. 
ELK

Asia Pacific Journals

- Affordability: With low disposable incomes, products need to be affordable to the rural consumer, most of who are on daily. A solution to this has been introduction of unit packs by some companies. Most of the shampoos and conditioners are available in smaller packs.

- Acceptability: The next challenge is to gain acceptability for the product or service. Therefore, there is a need to offer products that suit the rural market.

- Awareness: Building awareness is another challenge in rural marketing. A large part of rural India is inaccessible to conventional advertising media.

\section{Collective Decision making: Even today} the process of decision making takes place collectively. The purchase decisions of either goods or services are done together by all family members, which are mostly influence by family heads. Thus the marketing strategy cannot be individual oriented, it should be family oriented.

For instance, as part of total sanitation campaign by UNICEF, the ads were
ELK Asia Pacific Journals - Special Issue

ISBN: 978-81-930411-9-2

projected with the concept that reputation of the family is connected with the daughter-inlaw's attitude. This brings awareness of sanitation among all generations in a family.

5. Multi-culture: The myriad different uses of edible oil in India also reflect a multitude of different regional preferences and habits. For example, soybean oil is mainly used in Northern and central parts of India due to the availability of soybeans locally. Mustard oil is mainly consumed in North-eastern and Eastern regions of India as its pungency is desired, particularly for seafood. Palm oil dominates Southern India due to the warmer climate and sunflower oil is popular amongst the affluent classes.

Especially in rural areas there is more need of customization. For example, even today the people in rural India prefer homemade food. Thus a restaurant owner cannot introduce non-local flavors ignoring the local food culture.

6. Primary Sector: Rural economy is ruled by primary sector. This has larger impact on deciding the scope of acceptability and affordability of services. Dependency of most of the rural population on agriculture 
ELK

Asia Pacific Journals

and on other allied activites can attract only those service providers who can contribute for these activities. And the scope for accepting the other services reduces. At the time the main feature of agriculture sector in India is uncertainty where it is mostly dependent on monsoon rains. If there is no adequate rains, formers end up with losses and their purchasing power becomes limited.

To address these traditional challenges and to implement the services marketing in rural India there is more need of support from Government of India, respective state governments and panchayats as well as support from village youth in spreading the awareness about services availability.

Recent Challenges: Rural India is undergoing the phase of transmission towards economic development. In this context the service providers have to face some problems at the levels of planning and executing their marketing strategies. Some of them are as follows:

- Competitors are the biggest threat in the present globalization era, where a company not only competes with
ELK Asia Pacific Journals - Special Issue

ISBN: 978-81-930411-9-2

domestic competitors but also with MNCs.

- Rate of migration from villages to cities are increasing. If this continues the service provider who enters the rural market may find scarcity of consumers and has to windup his settings in that particular area

- Though the rural consumer doesn't demand or customized/ niche marketing, the nature of multiculture forces the service provider to follow niche marketing strategy that too at lower cost.

- Problem of affordability in rural areas compel the service seller to adopt new strategy of marketing. This can illustrate by the case study of Tata BP Solar product. Since people cannot afford to buy solar products outright, financing is important. Tata BP Solar has networked long and hard to get banks to give loans to villagers buying solar products. Through a unique initiative called Arunodaya, the company is trying to make banks aware of the positive cost-benefit ratio of solar products, and banks 
ELK

Asia Pacific Journals

have started giving loans. Arunodaya's objective is not to market solar products but to spread awareness about solar energy and its applications through seminars and workshops. "The customers are a byproduct of Arunodaya's activities," Tata BP Solar products have transformed lives in the villages of Punjab, Uttar Pradesh, Haryana, Kerala and Tamil Nadu. The idea is to make the sun shine on rural India, to brighten its future ${ }^{7}$.

- The other important challenge every service provider faces is decision of distribution channel, where there is every chance of duplication. To overcome these Dabur company started the program called Advanced Sales Training foe Retail Ascendance (ASTRA). Shopkeepers selling Dabur India's consumer products would now learn marketing through role-plays staged by professional actors at their shops. As part of a recent initiative titled Astra, advanced sales training for retail ascendance, FMCG major has recruited 75 sales and HR managers across the country who would
ELK Asia Pacific Journals - Special Issue ISBN: 978-81-930411-9-2

educate over 2,000 distribution channel partners of the firm about the complexities of sales and distribution through the audio-visual medium. Under Astra, Dabur has categorized its sales and distribution channels into finer segments, such as key grocers, mass grocers, chemist, wholesale, small outlet and modern trade. The programme will address specific needs and expectations of each channel in the areas such as, trade activation programmes, trade promotion programmes, brand/SKU focus, merchandising and managing channel conflict ${ }^{8}$.

- Macro economic conditions like inflation, rise in rate of interest rate reduces the availability of money with people. This in turn reduces largely the purchasing power of rural Indians. Thus they cannot prefer to get paid services.

- The change in the attitude of rural Indians is taking place at faster rate, this creating a confusion among service marketer either the change is setting a trend or just creating a fad situation at the stage of transmission. 
ELK

Asia Pacific Journals

This makes the service producer to wait before proceeding.

As rural markets evolve and competition in rural markets intensifies, companies will have to look for new approaches to harness this opportunity in ways that protect their margins while also growing revenue. Deploying the correct sales and distribution model can assist companies in driving profitable growth in a relatively short span of time. Rural masters will have to find ways to scale operations without hurting their bottom line. For a rural performer, the challenge will be to create differentiated offerings and brand loyalty to retain customers and sustain their business models. Rural voyagers will build their own ecosystems and brand awareness to acquire new customers. New entrants will travel their own paths to penetrate rural markets. By focusing on the specific needs, behaviours and preferences of the rural consumers, and by applying a systematic approach to market expansion, companies can accelerate their rural expansion journey.

Thus the reason for not able to exploit the opportunities in services market in rural areas is not because of resistant from the
ELK Asia Pacific Journals - Special Issue ISBN: 978-81-930411-9-2

villager to accept the services but because of the need of more research in understanding the rural consumer behavior for services and construction the marketing strategies accordingly.

\section{References:}

[1] American Marketing Association, "Definition of Marketing," www.marketingpower.com/AboutA MA/pages/DefinitionofMarketing.as px,2007; Lisa Keefe, "Marketing Defined," Marketing News, January 15, 2008, pp.28-29.

[2] Kotler Philip, Keller Kevin L., Koshy Abraham and Jha Mithileshwar (2013-14) Marketing Management: A South Asian Perspective (14 ${ }^{\text {th }}$ Edition) Pearson

Education Inc, page.322

[3] URL http://www.managementstudyguide.c om/definition-and-characteristics-ofservices.htm

[4] URL http://en.wikipedia.org/wiki/Services _marketing

[5] URL http://www.archive.india.gov.in/oute 
rwin.php?id=http://censusindia.gov.i

n/Metadata/Metada.htm

[6] URL

http://www.frontieradvisors.in/rural_ markets.html

[7] Sujata Agrawal (2006), Reaching out to rural India, URL

http://www.tata.co.in/company/articl esinside/m73PWIDIJmU=/TLYVr3 YPkMU=

[8] Ruchita Saxena, (2008) Dabur uses Astra to boost rural sales, URL http://www.business-

standard.com/article/companies/dabu r-uses-astra-to-boost-rural-sales108070401068_1.html

[9] Sanjay Dawar, (July 8, 2013), Marketing to rural India, URL http://www.businessstandard.com/article/management $/ \mathrm{m}$ arketing-to-rural-india113070700506_1.html 